\title{
RELAÇÕES EDUCATIVAS DE PROFESSORAS COM CRIANÇAS DE ZONA RURAL: UMA LEITURA DAS PRÁTICAS PEDAGÓGICAS EM UM CONTEXTO DE ESCOLA URBANA
}

\author{
RELACIONES EDUCATIVAS DE PROFESORAS CON NIÑOS DE ZONA \\ RURAL: UNA LECTURA DE LAS PRÁCTICAS PEDAGÓGICAS EN UN \\ CONTEXTO DE ESCUELA URBANA
}

\author{
EDUCATIONAL RELATIONS OF TEACHERS WITH CHILDREN LIVING IN \\ RURAL AREAS: A READING OF PEDAGOGICAL PRACTICES IN AN URBAN \\ SCHOOL CONTEXT
}

\author{
Luana ZANOTTO ${ }^{1}$ \\ Fernando Donizete ALVES ${ }^{2}$ \\ Aline SOMMERHALDER ${ }^{3}$
}

RESUMO: O artigo decorre de uma pesquisa concluída e focaliza práticas pedagógicas de duas docentes nas relações com um grupo de crianças residente em zona rural e que frequenta uma escola pública urbana. Objetivou compreender como ocorrem as relações educativas entre as professoras e as crianças no cotidiano das práticas pedagógicas. $\mathrm{O}$ grupo foi composto por onze crianças do terceiro ano do ensino fundamental e duas professoras. De perspectiva qualitativa, foi realizada observação participante em dois espaços escolares, em que conviviam crianças e professoras. Com registro em diários de campo, todo o material coletado foi categorizado por meio da análise de conteúdo e discutido à luz da literatura escolhida. Destacam-se relações positivadas entre professoras e crianças, expressos pelas ações das crianças em que ir à escola possibilita a troca de saberes entre pares, bem como apreender conhecimentos escolares. Os resultados revelaram ainda dificuldades enfrentadas nas práticas pedagógicas com a população rural inserida na escola urbana, sobretudo no que concernem diferenças de contextos de vida que perpassam o espaço rural onde vivem as crianças. Há uma implicação nos saberes experienciais construídos nos intramuros escolares, os quais remetem à reflexão sobre a formação de professores para atuar com crianças de zona rural.

PALABRAS-CHAVE: Práticas pedagógicas. Crianças de zona rural. Relações educativas. Escola de ensino fundamental urbana.

${ }^{1}$ Universidade Federal de São Carlos (UFSCAR), São Carlos - SP - Brasil. Doutoranda no PPG em Educação. E-mail: luanazanotto@yahoo.com.br.

${ }^{2}$ Universidade Federal de São Carlos (UFSCAR), São Carlos - SP - Brasil. Doutorando no PPG em Educação.E-mail: fdalves@ufscar.br.

${ }^{3}$ Universidade Federal de São Carlos (UFSCAR), São Carlos - SP - Brasil. Professora do Departamento de Teorias e Práticas Pedagógicas. Docente do Programa de Pós-ggraduação em Educação.Coordenadora do Grupo de Estudos e Pesquisas sobre Processos Educativos de Crianças/CNPq. E-mail: sommeraline1@gmail.com.

RIAEE - Revista Ibero-Americana de Estudos em Educação, Araraquara, v.12 , n.4 ,p. 2058-2071, out./dez. 2017. 
RESUMEN: El artículo se deriva de una investigación concluida y focaliza prácticas pedagógicas de dos docentes en las relaciones con un grupo de niños residente en zona rural y que frecuenta una escuela pública urbana. Objetivó comprender cómo ocurren las relaciones educativas entre las profesoras y los niños en el cotidiano de las prácticas pedagógicas. El grupo estuvo compuesto por once niños del tercer año de la enseñanza primaria y dos profesoras. De perspectiva cualitativa, se realizó observación participante en dos espacios escolares, en los que conviven niños y profesoras. Con registro en diarios de campo, todo el material recolectado fue categorizado por medio del análisis de contenido y discutido a la luz de la literatura escogida. Se destacan relaciones positivas entre profesoras y niños, expresados por las acciones de los niños en que ir a la escuela posibilita el intercambio de saberes entre pares, así como aprehender conocimientos escolares. Los resultados revelaron aún dificultades enfrentadas en las prácticas pedagógicas con la población rural insertada en la escuela urbana, sobre todo en lo que conciernen diferencias de contextos de vida que atravesan el espacio rural donde viven los niños. Hay una implicación en los saberes experienciales construidos en los intramuros escolares, los cuales remiten a la reflexión sobre la formación de profesores para actuar con niños de zona rural.

PALAVRAS CLAVE: Prácticas pedagógicas. Niños de zona rural. Relaciones educativas. Escuela de enseñanza fundamental urbana.

ABSTRACT: The article stems from a completed research and focuses on practices of two teachers in dealing with a group of children living in rural areas and attending an urban public school. Aimed to understand how occur the educational relationships between teachers and children in daily teaching practices. The group was composed of eleven children in the third grade of elementary school and two teachers. Of the qualitative perspective, participant observation was performed in two school spaces where children lived with teachers. With record in field diaries, all material collected was categorized by content analysis and discussed in the light of the chosen literature. Noteworthy are positive relationships between teachers and children, expressed by the actions of children to go to school and the enables the exchange of knowledge among peers and learn school knowledge. The results also revealed difficulties in pedagogical practices with the rural population inserted in the urban school, especially in differences in living contexts that pervade the countryside where children live. There is an implication in the experiential knowledge built in school, which lead to the reflection on the training of teachers to work with countryside children.

KEYWORDS: Pedagogical practices. Rural children. Educational relations. School of basic urban education.

\section{Introdução}

O presente artigo resulta de uma pesquisa acadêmica concluída e focaliza práticas pedagógicas de duas professoras - pedagoga e educadora física - na relação com um grupo de crianças residente em zona rural, inserido em uma escola municipal situada em perímetro urbano de uma cidade do interior do Estado de São Paulo. Teve 
por objetivo compreender como ocorrem as relações educativas entre as professoras e as crianças no cotidiano das práticas pedagógicas.

A discussão acadêmica e científica acerca da temática da educação do, no e para o campo não é recente na área das Ciências Humanas, especialmente na Educação (SANTOS, 1988; DAMASCENO; BESERRA, 2004; STROPASOLAS, 2012). O anseio de pesquisadores em compreender as relações estabelecidas entre as populações da cidade e as populações do campo soma-se às inquietudes e à ausência de reconhecimento e valorização das condições sociais, políticas e econômicas dos sujeitos pertencentes às zonas rurais dos municípios.

O ponto que despertou interesse à investigação dessa temática compreendeu a construção da concepção do cenário rural no imaginário da sociedade brasileira estar frequentemente associada à ideia de atraso cultural e tecnológico e/ou como espaço de não desenvolvimento e sem acesso às infraestruturas e serviços básicos. Segundo Biazzo (2008) a reprodução da hierarquia 'urbano x rural' se realiza a partir da construção estigmatizante de que, residir em zonas rurais representa inferioridade social e cultural, processo manifesto, também, na percepção dos distintos estilos de vida.

Nesse sentido, os sujeitos que vivem a sua infância e juventude em espaços rurais são afetados por uma caracterização pejorativa do seu cotidiano, isto é, a vinculação destes territórios com o atraso e o isolamento social e o julgamento da identidade social como 'colonos', 'roceiros' e 'peões'.

Em meio a este discurso, consideramos que tais representações necessitam ser problematizadas, desnaturalizadas e, obviamente, questionada por todos aqueles que interagem, ou não, com o público de zona rural. Para Leite (2002), a escola enquanto espaço destinado ao convívio social, também comunga de concepções e ideários mistificados acerca da população infantil rural, pois em âmbito escolar urbano propriamente, as relações geradas entre as crianças e professores podem ser expressas por certo distanciamento entre a visão de mundo urbana e a visão de mundo rural. Tal distinção de contextos de vida, na relação entre criança-criança pode acarretar em posturas de preconceitos e discriminações, desencadeando sentimentos de inferioridade e de marginalização. Do mesmo modo, na relação criança-professor, por vezes, originam-se processos de ensino e de aprendizagem descontextualizados e desconexos com os anseios e necessidade das crianças de zona rural.

Partiu-se da consideração de que a instituição escolar, de modo integral, possui importância ímpar no processo de problematização desses conceitos e de acolhimento 
das diferentes culturas, fenômeno que atribui à escola um lugar, tempo e espaço para construção e reconstrução cultural.

\section{Caminho metodológico}

A pesquisa foi realizada em uma Escola Municipal de Ensino Fundamental (EMEF) de uma cidade do interior do estado de São Paulo. Trata-se da única instituição escolar da cidade destinada a ofertar vagas para estudantes entre seis e dez anos de idade, ou seja, crianças do Ensino Fundamental dos anos iniciais, advindas da zona rural da região.

A pesquisa contou com a participação de 11 crianças entre oito e nove anos de idade, sendo sete meninas e quatro meninos, estudantes da única turma do terceiro ano do ensino fundamental da escola. A escolha por essa turma ocorreu em virtude destas crianças possuírem um tempo maior em anos frequentando a mesma escola, nesse caso, dois anos ou mais, contribuindo para ampliação das experiências em âmbito escolar. Somaram-se ao grupo de crianças participantes as duas professoras da turma: uma pedagoga, que exercia a docência diariamente com as crianças e que atua nessa escola desde 2000 e, uma educadora física, recentemente ingressa ao quadro de docentes, sendo responsável por duas horas de aulas semanais com essa turma.

O estudo sustentou-se na abordagem qualitativa (ANDRÉ, 1994), sendo descritivo e exploratório. Como procedimento metodológico realizou-se observação participante que ofereceu um maior contato com os participantes da pesquisa, igualmente, favorecendo os estreitamentos de vínculos pautados em uma relação de confiança que permitiu chegar mais próximo da realidade social inserida (LUDKE; ANDRÉ, 2012).

Para o registro dos dados foram utilizadas notas de campo em diários de campo, na perspectiva considerada por Bogdan e Biklen (1994, p. 152), "notas de campo são relatos escritos daquilo que o investigador ouve, vê, experiência e pensa no decurso da recolha refletindo sobre os dados de um estudo qualitativo". Os diários de campo foram elaborados diariamente e de maneira detalhada, decorrente do acompanhamento e por meio da observação participante da rotina das crianças e atividade pedagógicas desenvolvidas, de modo a registrar de forma próxima ao real os episódios vivenciados em cada inserção na unidade escolar. 
Buscando estar presente nas vivências apreendidas pelas crianças, sobretudo nas práticas pedagógicas desencadeadas pelas professoras, optou-se por realizar as inserções em dois espaços escolares, na sala de aula e durante as aulas de educação física, na quadra poliesportiva. As inserções no campo de pesquisa ocorreram com uma frequência de duas a três vezes por semana, em geral distribuídas entre as segundas, quartas e sextas-feiras no horário compreendido das 7 horas às 10 horas do período da manhã, ao longo de 4 meses seguidos, totalizando 32 inserções de pesquisa de campo.

Importante ressaltar que as professoras e os responsáveis pelas crianças assinaram o Termo de Consentimento Livre e Esclarecido (TCLE). As crianças, além do consentimento dos respectivos responsáveis, indicaram seu interesse em participar pelo Termo de Anuência Livre e Esclarecido (TALE). A pesquisa também teve aprovação do Comitê de Ética em Pesquisa com Seres Humanos, da Universidade. Os nomes verdadeiros das participantes da pesquisa foram alterados por nomes fictícios escolhidos por elas próprias, para garantir sigilo da identidade e privacidade das crianças e professoras.

Para a organização, análise e discussão dos dados, todo material produzido na fase de coleta foi agrupado, via densas leituras e foram feitas análises por meio das bases teóricas da análise de conteúdo, proposta por Bardin (2009). Neste processo buscou-se abstrair o sentido e o significado expressos nas mensagens, sejam elas orais, escritas, gestuais, silenciosas, figurativas ou documentais. Após a realização de todas as etapas descritas por este método, especialmente à identificação das unidades de registro e de contexto contidas nos diários de campo, emergiram duas categorias temáticas articuladas, assim nomeadas: (a) Relações crianças-professoras no cotidiano escolar: encontros e desencontros e (b) Aspectos educativo-pedagógicos nas práticas docentes. A seguir, tais categorias serão apresentadas e discutidas à luz da literatura escolhida.

\section{Resultados e discussão}

Na primeira categoria: Relações entre crianças e professoras no cotidiano escolar: encontros e desencontros são apresentados elementos de convivência entre as professoras e as crianças no dia-a-dia da escola, particularmente no contexto de sala de aula. As crianças demonstraram ter abertura para dialogar com ambas as professoras, sendo que suas vozes foram ouvidas e consideradas, com respeito, pelas docentes. Durante as inserções, foram observados episódios em que, tanto as crianças quanto os

RIAEE - Revista Ibero-Americana de Estudos em Educação, Araraquara, v.12 , n.4 ,p. 2058-2071, out./dez. 2017. 
adultos, puderam falar sobre si mesmos e compartilhar curiosidades sobre o momento vivido ou sobre acontecimentos da vida particular. $\mathrm{O}$ excerto abaixo indica uma situação em que as crianças demonstraram ter conhecimentos sobre a vida particular da professora, com formação em pedagogia:

A inspetora abre a porta da sala de aula e pergunta à professora: "seu pai esta bem? Ele melhorou?" Essa questão foi feita em voz alta, possibilitando com que as crianças ouvissem. Imediatamente, Letícia pergunta: "ah, é verdade... Professora, seu pai já tá bonzinho?!" Percebi que as crianças já sabiam que o pai da professora estava doente. Considerei interessante saber que as crianças têm conhecimento parcial sobre a vida pessoal da professora, já que, por caráter da própria docência, o professor tende a ter uma participação maior na vida das crianças do que o contrário (DIÁRIO DE CAMPO XVI, 2014).

Os espaços de aproximação de vidas entre professora-crianças possibilitaram que os vínculos entre elas sejam ainda mais estreitos, o que pode favorecer e fortalecer o processo de ensino e de aprendizagem. Segundo Sommerhalder e Alves (2012) o professor torna-se objeto de desejo da criança, por quem desenvolve grande empatia. É a pessoa do professor que está em primeiro plano. Esse processo desencadeia certa afinidade entre criança e professor, o que pode fazer com que a criança se apaixone pelo conteúdo pedagógico, a partir do modo como o professor lhe apresenta, somada à construção de vínculos afetivos com o mesmo.

A análise da convivência com o grupo permitiu compreender o grande empenho e interesse da turma em apreender os conteúdos escolares, fato possivelmente justificado pelo contato estreito e de amorosidade pela professora com formação em pedagogia, e que remete a indícios de que a aprendizagem se resulta possível a partir da presença do outro, neste caso, da professora como o outro humano na relação educativa.

Quanto às relações estabelecidas com a professora de educação física, a partir da convivência com o grupo, a mesma expressou importante preocupação em incentivar às crianças na realização de práticas de atividades físicas (campo de conhecimento do componente curricular em questão), ao mesmo tempo em que assumiu posturas abertas para o diálogo e tentativas de criar vínculos estreitos com as crianças, já que se encontravam apenas duas vezes na semana.

Interessante destacar que esta professora assiduamente participava de brincadeiras iniciadas e desenvolvidas pelas crianças em momentos de interação livre entre pares (CORSARO, 2011). Contudo, e ainda que possibilitasse a criação e 
organização de momentos lúdicos, a professora não avançava na discussão daquilo que era produzido pelo coletivo de crianças da zona rural. Como exemplo, pôde-se observar a interação de um grupo de crianças em uma dessas brincadeiras.

Samuel, Violeta e Raul estão brincando de cerquinha, em que Violeta é o filhote do cachorro que acabou de dar cria. Samuel é quem vem dar comida para as galinhas e ficam ao lado da cerca dos filhotes. Raul, também como filhote, rola no chão da quadra demonstrando estar faminto e esperando o dono chegar com a comida. Em meio a essa brincadeira, a professora chegou, dizendo em tom alto de voz para que os três se levantassem, justificando que o ficar ali - rolando iria deixá-los sujos para voltar para sala de aula [...]. Pediu para eles brincarem em pé e não de animais [...] (DIÁRIO DE CAMPO IV, 2014).

Tal momento poderia ter sido contemplado para a aproximação da professora com estas crianças, questionando-as sobre a origem da história das cercas e do papel do animal em seus respectivos espaços, assim, podendo-se aproximar um pouco mais do contexto extraescolar, vivenciado por elas. Da mesma forma, compreender a brincadeira pode ser um meio importante para conhecer as demandas e interesses das crianças, o que anuncia uma possibilidade maior de aproximação entre os anseios das crianças e o seu planejamento pedagógico. Isso significa partir do "saber de experiência feito" das crianças, termo que para Freire (1996, p. 53) refere-se às experiências de vida trazidas pelos sujeitos, as quais devem ser consideradas em seus contextos históricos, e traduzem a leitura de mundo dos sujeitos, se tomadas como ponto de partida nas relações humanas e educativas.

Além disso, o interesse dessa educadora poderia contribui no sentido de melhorar o diálogo com as crianças, tornar o ambiente escolar mais acolhedor. De acordo com Freire (1993, p. 22) cabe à escola vislumbrar um espaço acolhedor e multiplicador de atitudes democráticas, como a de ouvir as crianças e acolher suas sugestões. Neste sentido, destacam-se alguns aspectos em que as crianças ofertaram aberturas para que as professoras, cada vez mais, compreendessem e se colocassem ao encontro dos aspectos culturais expressos pelas crianças. De um modo peculiar, as crianças buscavam aproximar as atividades propostas pelas professoras com seus contextos de experiências, de modo que a ação abordada em sala ou na quadra estabelecesse algum sentido e significado à vida cotidiana delas.

Em uma aula de educação física, a professora pediu ajuda para carregar os materiais cones até o depósito da escola. Samuel, rapidamente, se ofereceu para ajudar e

RIAEE - Revista Ibero-Americana de Estudos em Educação, Araraquara, v.12 , n.4 ,p. 2058-2071, out./dez. 2017. 
começou a dizer que, em sua casa, também ajuda seu pai com as tarefas. "O menino conta que ainda só pode ajudar a levar sacos de esterco para a horta de sua casa, mas que sua vontade mesmo é de poder guiar o caminhão de cana logo [...]" (DIÁRIO DE CAMPO XV, 2014).

Nesse excerto de diário de campo, verifica-se que após lançar o pedido, a professora logo é atendida pela criança Samuel, que aproveita a situação para socializar parte de sua rotina cotidiana. As falas corriqueiras das crianças necessitam da escuta atenta dos adultos, como forma de estarem abertos ao que o outro tem a dizer, reconhecendo o valor das ações do ponto de vista e da interpretação deste outro, seja em momentos de atividades escolares direcionadas ou em momentos como o guardar dos materiais. Segundo Rinaldi (2012, p. 125), a escuta atua como premissa de qualquer relação de aprendizagem "- aprendizado que é determinado pelo 'sujeito aprendiz' e toma forma na mente desse sujeito por meio da ação e da reflexão". A escuta protagoniza meios para saber e aguçar falas acerca das experiências vividas em ambientes extraescolares, as quais enriquecem a prática cotidiana de ensinar e de aprender.

Observou-se que ambas as professoras colocaram-se à disposição das crianças, em uma postura dialética e comprometida com o ofício. Entretanto, nas relações desencadeadas entre elas, raramente evidenciou-se uma discussão mais aprofundada do universo e das referências culturais das crianças de zona rural, desta forma, gerando alguns desencontros hierárquicos e culturais. Por fim, há o reconhecimento de que os espaços para as crianças expressarem os modos próprios de sentir, pensar e agir, suas formas de se relacionar com os outros não foram negligenciados, porém poderiam ser melhor aproveitados ou oportunizados educativamente, pelas docentes.

A segunda categoria, intitulada: Aspectos educativo-pedagógicos nas práticas docentes anuncia práticas educativo-pedagógicas entendidas como ações docentes que transcendem apenas a preocupação em transmitir conhecimentos escolarizantes nas crianças, ou seja, estão atreladas às ações do educar, para além da absorção passiva de conhecimentos reconhecidamente como escolares. Tais práticas estiveram presentes nas ações das professoras. A título de exemplo, destacamos a prática de leitura de história feita pela professora pedagoga, sobre a festa dos animais:

[...] o personagem pássaro ficou gozando da tartaruga, pois está não iria conseguir chegar ao céu, já que ela não poderia voar até lá. Neste momento, a professora faz uma pausa e perguntou às crianças: "quais

RIAEE - Revista Ibero-Americana de Estudos em Educação, Araraquara, v.12 , n.4 , p. 2058-2071, out./dez. 2017. 
soluções podem ser dadas para que a tartaruga vá à festa?" Patrick começou a dizer em voz alta: "não tem o que fazer, se ela não "avoa" porque não tem asa, então ela não vai e vai ficar pra trás mesmo, profe". A professora intervém dizendo que, na vida, nem sempre temos as melhores possibilidades para conseguir com facilidade o que desejamos, mas que não podemos desistir antes de procurarmos soluções. Ouvindo o comentário feito pela professora, Henrique então sugeriu: "porque ela não chama outro animal grande que voa e sobe nele e vai junto?!” (DIÁRIO DE CAMPO XV, 2014).

Ao aproveitar o contexto da história para refletir algumas situações da vida cotidiana, a prática pedagógica da professora transformou a sala de aula em um espaço oportuno para inter-relações de conhecimento e autoconhecimento, ancorado em meio às estratégias de ensino propostas pelo documento: Ensino Fundamental de nove anos: orientações gerais (BRASIL, 2004), os quais estão pautados na aprendizagem da leitura e escrita. A professora almejou que as crianças apreendessem os conteúdos formalizados, por exemplo, ao interpretar o texto e, ainda, superou tal objetivo ao buscar construir junto à elas, alguns valores à vida.

Em outra situação, ao terminar de colocar os escritos na lousa, a professora circulou entre as carteiras para ver quem estava concluindo a atividade, até deter-se aos afazeres de Felipe. A criança vive na fazenda Santa Helena, é pouco frequente nas aulas e, por vezes, a professora pede a sua atenção/concentração nas atividades escolares e mais empenho nas tarefas de casa.

[...] parando ao lado de Felipe, a professora questionou: "você esta treinando escrever em casa? Por que, olha, a coisa tá feia, desse jeito vai chegar o final do ano e nada". Felipe apenas balança a cabeça com um gesto positivo. O menino demonstra-se ainda mais 'fechado'/encolhido na carteira e continua olhando fixamente para lousa, transferindo as letras para o caderno. Ela aproveitou o contexto para dizer que não se pode trocar a letra $L$ pela $R$, sendo que palavrinhas como 'plástico' e 'folga' não podem ser escritas e nem faladas 'prástico' e 'forga' [...] (DIẢRIO DE CAMPO VI, 2014).

A partir da análise do excerto, torna-se possível compreender que a professora tentou não reduzir os afazeres pedagógicos em situações puramente técnicas, ao demonstrar-se atenta e preocupada com a aquisição da escrita por essa criança. Contudo, culmina em não considerar a existências da subjetividade e necessidades próprias do menino, especialmente, ao modo coloquial da fala e de linguagens compatíveis aos saberes de origem das crianças. Distancia-se de uma mediação pedagógica que contemple também a problematização destas questões.

RIAEE - Revista Ibero-Americana de Estudos em Educação, Araraquara, v.12 , n.4 ,p. 2058-2071, out./dez. 2017. 
Continuando o processo investigativo, focalizamos a análise de uma inserção que contribuiu de forma ímpar para a compreensão e discussão de como ocorreu o tratamento das atividades escolares focadas no contexto rural. $\mathrm{O}$ fragmento de diário de campo a seguir descreve o contexto da atividade:

A professora anuncia que irá retomar a leitura do livro de ontem. A obra intitula-se "Sai da frente vaca brava" e conta a história de vida de uma menina chamada Naná, de dez anos, que morava na fazenda, numa casa bem pobrezinha e afastada da cidade [...]. A personagem tinha que ir a pé para a escola. Num dado momento, a professora interrompeu a leitura, dizendo: "não era como vocês que tem o ônibus, ela ia andando, sozinha. E vocês tem ônibus que passa quase que na frente de casa e tem um monte de gente que vive faltando". As crianças ouvem o comentário feito pela professora em silêncio. Retoma a história e conta que Naná acaba chegando muito cansada de tanto andar e, por isso, não consegue se concentrar nas lições. Um belo dia, no caminho à escola, Naná encontrou uma vaca muito brava e, por isso, teve que desviar o caminho e chegou depois do recreio na escola. Novamente, a professora interrompeu partes da história e questionou as crianças sobre o que estavam achando e as incentivou a dizerem como pensavam que seria o final da história. Kauan, Letícia e Julieta foram os mais participativos e foram tecendo outros contextos à história, colaborando com a professora na construção da aprendizagem [...]. A história foi tomando rumo final. A vaca encontrada no caminho acabou virando amiga de Naná e a história abarcou conceitos sobre a escassez de recursos para as pessoas que moram afastadas da cidade e sobre a exploração de mão de obra infantil [...]. (DIÁRIO DE CAMPO XXVI, 2014).

O principal objetivo do trabalho da professora de sala de aula foi ofertar uma condição singular para que as crianças pudessem se reconhecer como parte de uma determinada cultura e construir identidades afirmativas à medida que se reconhecessem, em partes, no conteúdo abordado na história. Sendo assim, ao final da leitura ela fez uma relação entre a história e o contexto de vida das crianças de zona rural, dizendo: "tem muito a ver com vocês, pois também acordam cedo para esperar o ônibus passar, encontram obstáculos para chegar na escola e às vezes ainda atrasam ou faltam no dia [...]” (DIÁRIO DE CAMPO XXVI, 2014).

A breve discussão desencadeada entre crianças e professora possibilitou deter maior compreensão sobre a realidade rural, refletindo sobre ela. Fragmentos do mesmo Diário de Campo revelaram ainda a interpretação dessas crianças:

"gostei do livro porque a vaca ficava na escola junto com as crianças e eram amigas e também que o prefeito só faz as coisas boas quando vai um monte de gente lá falar e reclamar" Letícia (8 anos); e também de Maria Luiza (9 anos): "gostei de que as crianças vão todas juntas 
lá pra fazenda da Naná e lá brincam de tudo que nem a gente aqui" (DIÁRIO DE CAMPO XXVI, 2014).

Sabe-se que o cuidado pedagógico da professora em contemplar uma história sobre parte do universo rural refletiu em seu compromisso quando realizou uma mediação pedagógica que incluiu um espaço acolhedor na escola e com respeito às multiculturalidades. Tal mediação realiza diálogo com o pensamento de Leite (2002), que atendendo a importância em respeitar e compreender as diferenças como marca da condição humana, ilumina o papel cultural da escola e defende o encontro de culturas, como forma de combate a hierarquização entre elas ou subordinação de uma à outra.

Ainda que as crianças tenham conseguido estabelecer correlação com a história, as Diretrizes Operacionais para a Educação Básica nas Escolas do Campo (BRASIL, 2002) salientam que o reconhecimento do modo próprio de vida social, da diversidade e da identidade da população rural não pode ser feita de modo fragmentado e descontextualizado das verdadeiras condições de vida do público com o qual atua. Em outras palavras, salienta-se que o diálogo sobre o contexto de vacas e exploração de mão de obra infantil não pertence às realidades de vida das crianças desta escola, já que estas são filhos de trabalhadores assalariados na lavoura de cana de açúcar e possuem a moradia na região rural, concedida pelos patrões, para que os familiares trabalhadores estejam integralmente próximos as ambiente de trabalho.

Ao empreender atividades que pouco se aproximam do contexto de vida das crianças, estar-se-á colaborando ainda mais com mitos e estigmas de que a vida no campo é vivida de uma única forma, universalizante e uniformalizante. Desta forma, a compreensão do universo cultural e especificidades dos sujeitos que compõe a escola são imprescindíveis para que a mediação pedagógica seja pertinente. Neste quesito, ainda cabe ressaltar que o projeto político pedagógico desta escola, demonstra-se atento e articulado à realidade do seu alunado, de modo que a comunidade escolar venha a conhecer melhor e valorizar a cultura local. Entretanto, em meios a práticas pedagógicas, por vezes, surgiram alguns equívocos no processo de desenvolvimento ou vivência do mesmo.

Ao longo da pesquisa de campo foi sendo anunciado o emprego de práticas educativo-pedagógicas, num exercício comprometido das docentes na constituição de conhecimentos escolares e da apreensão de valores inerentes à formação humana. Neste processo, foi observada a atuação dessas crianças como agentes detentoras das unidades

RIAEE - Revista Ibero-Americana de Estudos em Educação, Araraquara, v.12 , n.4 , p. 2058-2071, out./dez. 2017. 
de ensino, bem como de formação de valores e condutas socialmente desejáveis na cultura escolar urbana.

\section{Considerações finais}

Aproximando das práticas pedagógicas dessas professoras, conclui-se que elas exerceram ações didáticas diretamente com as crianças, na perspectiva de formá-las para a vida em sociedade. Nesse sentido, Sommerhalder e Alves (2012, p. 241) aclaram que o processo empregado pelas docentes "implica incorporar valores, comportamentos, conceitos, enfim, saberes que possibilitam à criança constituir-se como sujeito no interior de um determinado contexto sociocultural".

Assim, essa pesquisa evidenciou que, ao mesmo tempo, em que houve uma estruturação de práticas pedagógicas com foco na constituição de conteúdos escolarizantes voltados à formação integral do ser humano, pouco se verificou a oportunidade para as crianças expressarem/aprofundarem saberes oriundo de seus pertencimentos culturais. As relações entre crianças e professoras no ambiente escolar permitiu que as crianças coordenassem suas vontades e desejos com expectativas próprias, ao passo que as ações docentes raramente aproveitaram tais manifestações para abordar valores e práticas emergidas do contexto de vida das crianças de zona rural.

Se no campo discursivo da educação, a escola é compreendida como um espaço de apropriação e constituição de conhecimentos e habilidades que ultrapassam o âmbito da linguagem, da leitura e escrita, das lógicas matemáticas, de desenvolvimento de aspectos físicos e motores; visando reconhecer as crianças como sujeitos, valorizando os espaços físicos e sociais aos quais elas estão inseridas, bem como proporcionando aprendizagens sociais, culturais e de valores (BRASIL, 2004), considera-se necessário aprofundar a discussão sobre os processos de formação de professores que, possivelmente, conviverá com crianças de zona rural em suas práticas profissionais cotidianas.

A discussão é fundamental, pois, para além de sugerir à formação docente um processo dinâmico, cíclico e inacabado, oferta ao exercício docente especificidades da demanda no campo, no que concerne às raízes históricas e políticas desta população. Como grande mérito, trazendo as crianças e suas culturas para o centro das práticas 
pedagógicas nas distintas etapas de ensino da educação básica, deste modo, não se restringindo ao contexto de vidas e saberes, majoritariamente urbano.

Por fim, compreende-se a escola como um espaço que busca constituir, junto com os sujeitos que dele pertence, bases para muitas aprendizagens necessárias aos entendimentos, reflexões e enfrentamentos de situações cotidianas. Para tanto, defendese a construção de práticas pedagógicas que reconheçam e valorizem as culturas de pares, possibilitando um lugar de encontro de saberes de pessoas.

\section{REFERÊNCIAS}

ANDRÉ, M. E. D. de. Etnografia da prática escolar. 11 ed. Campinas: Papirus, 2004.

BARDIN, L. Análise de conteúdo. Lisboa: Edições 70, 2009.

BIAZZO, P. P. Campo e rural, cidade e urbano: distinções necessárias para uma perspectiva crítica em geografia agrária. Encontro nacional de grupos de pesquisa ENGRUP, $4^{\circ}$, 2008. Anais... São Paulo: USP, p. 132-150, 2008. Disponível em: $<$ http://www.geografia.fflch.usp.br/inferior/laboratorios/agraria/Anais\%204ENGRUP/tr abalhos/biazzo_p_p.pdf>. Acesso em: 01 jun. 2016.

BOGDAN, R. C.; BIKLEN, S. K. Notas de campo. In: BOGDAN, R. C.; BIKLEN, S. K. Investigação qualitativa em educação. Porto: Porto Editora, 1994, p. 150-175.

BRASIL. Ministério da Educação e do Desporto. Ensino Fundamental de nove anos: orientações gerais. Brasília, 2004.

BRASIL Conselho Nacional de Educação. Câmara de Educação Básica. Diretrizes operacionais para a educação básica nas escolas do campo. Brasília, 2002.

CORSARO, W. A. Sociologia da infância. 2 ed. Porto Alegre: Artmed, 2011.

DAMASCENO, M. N; BESERRA, B. Estudos sobre educação rural no Brasil: estado da arte e perspectivas. Educação e Pesquisa, São Paulo, v.30, n.1, p. 73-89, jan./abr. 2004. Disponível em: <http://www.revistas.usp.br/ep/article/view/27925/29697>. Acesso em: 05 jun. 2016.

FREIRE, P. Professora sim tia não: cartas a quem ousa ensinar. 1 ed. São Paulo: Olha d'Água, 1993.

FREIRE, P. Pedagogia da autonomia: saberes necessários a prática educativa. São Paulo: Paz e Terra, 1996.

LEITE, M. I. F. P. Repensando a escola - com a palavra: a crianças da área rural. PróPosições, Campinas, v. 13, n.1 (37), p. 176-185, 2002. Disponível em:

RIAEE - Revista Ibero-Americana de Estudos em Educação, Araraquara, v.12 , n.4 , p. 2058-2071, out./dez. 2017. 
<http://www.proposicoes.fe.unicamp.br/proposicoes/textos/37-artigos-leitemifp.pdf $>$. Acesso em: 01 jun. 2016.

LUDKE, M; ANDRÉ, M E. D. A. Pesquisa em educação: abordagens qualitativas. São Paulo: E.P.U., 2012.

RINALDI, C. Diálogos com Reggio Emilia: escutar, investigar e aprender. Tradução: Vania Cury. $1^{\circ}$ ed. São Paulo: Paz e Terra, 2012.

SANTOS, M. Metamorfose do espaço habitado. São Paulo: Hucitec, 1988. 112p.

SOMMERHALDER, A; ALVES, F. D. Infância e Educação Infantil: aspectos inconscientes das relações educativas. Paidéia, Ribeirão Preto, v. 22, n. 52, 241-249, 2012. Disponível em: <http://www.scielo.br/pdf/paideia/v22n52/10.pdf >. Acesso em: 15 jun. 2016.

STROPASOLAS, V, L. Os significados do corpo nos processos de socialização de crianças e jovens do campo. In: ARROYO, M. G.; SILVA, M. R. da. Corpo Infância: exercícios tensos de ser criança. Petrópolis, RJ: Vozes, 2012. p. 153-184.

\section{Como referenciar este artigo}

ZANOTTO, Luana.; ALVES, Fernando Donizete.; SOMMERHALDER, Aline. Relações educativas de professoras com crianças de zona rural: uma leitura das práticas pedagógicas em um contexto de escola urbana. Revista Ibero-Americana de Estudos em Educação, Araraquara, v. 12, n. 4, p. 2058-2071, out./dez. 2017. Disponível em: <http://dx.doi.org/10.21723/riaee.v12.n4.out./dez.2017.8915>. E-ISSN: 1982-5587.

Submetido em: 16/09/2017

Revisões requeridas: 02/07/2017

Aceite em: 11/07/2017 